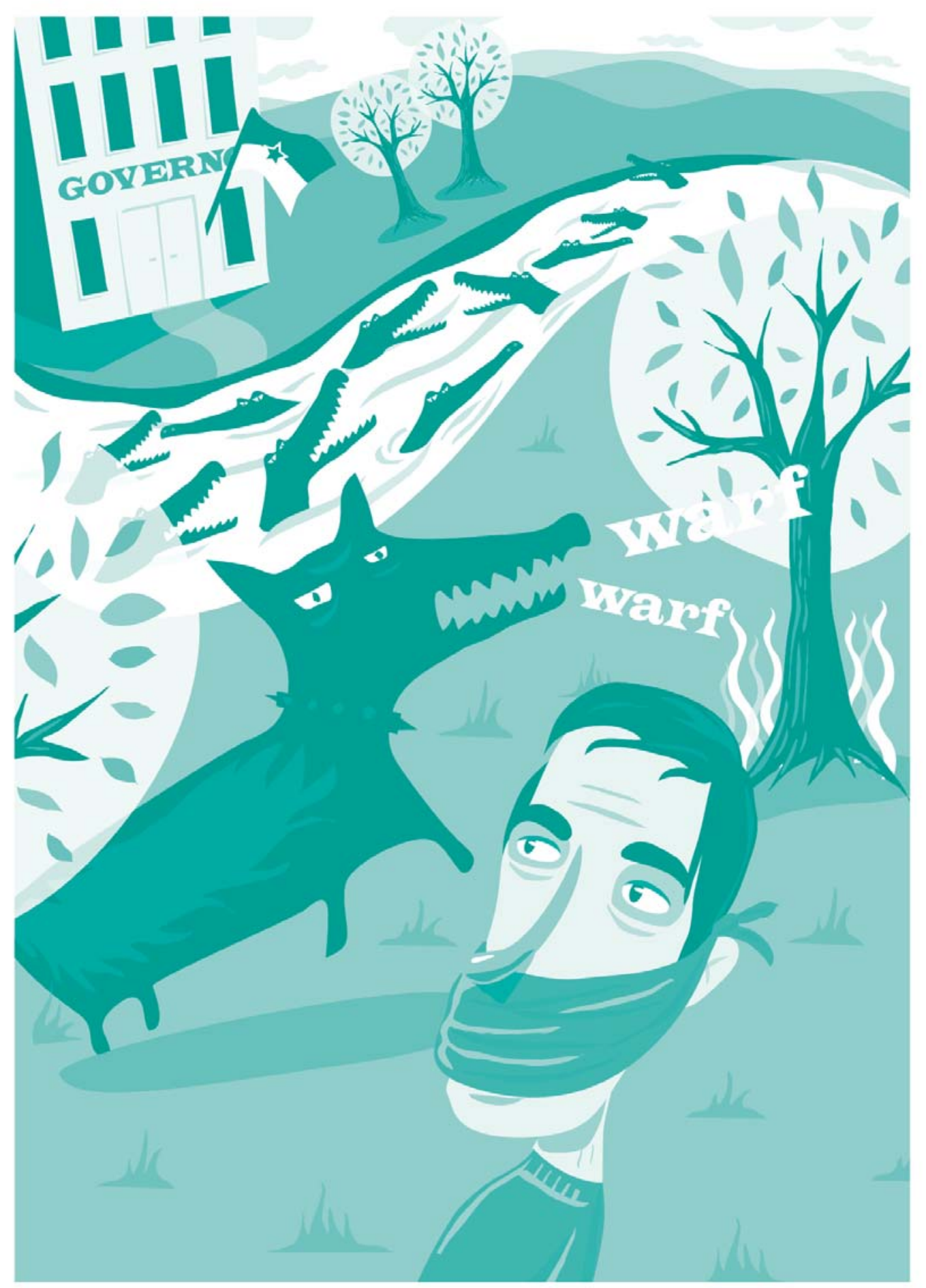




\section{Comunicação Governamental: em busca de um alicerce teórico para a realidade brasileira}

Mariângela Furlan Haswani

- Mestre em Ciências da Comunicação pela Escola de Comunicações e Artes da Universidade de São Paulo (ECA-USP)

- Graduada em Jornalismo pela Faculdade de Comunicação Social Casper Líbero

- Docente do Curso de Relações Públicas, Propaganda e Turismo da ECA-USP

- Atuou nas áreas de comunicação e imprensa das administrações públicas estatais direta e indireta na cidade de São Paulo (Secretaria de Administração, Câmara Municipal e CET) e como consultora de comunicação em campanhas eleitorais e marketing político em vários estados brasileiros, além de sindicatos e outras organizações públicas não-governamentais

- haswani@usp.br 
Resumo

O artigo foca a comunicação governamental numa conjuntura de profunda crise de legitimidade institucional. Nesse cenário, e considerando a história da formação do Estado brasileiro como um fator a dificultar as mudanças necessárias, apresenta as propostas de alguns autores italianos, também desenvolvidas no bojo das crises daquele país e que podem contribuir na elaboração de um modelo brasileiro de comunicação estatal.

PALAVRAS-CHAVE: COMUNICAÇÃO PÚBLICA - COMUNICAÇÃO GOVERNAMENTAL • COMUNICAÇÃO ESTATAL

\section{Abstract}

The article focuses on governmental communication in a conjuncture of a deep crisis of institutional legitimacy. In this scenario, and considering the history of the formation of the Brazilian State as a factor that impairs the necessary changes, it presents the proposals of some Italian authors, which were also conceived in the middle of the crises in that country and can contribute to the creation of a Brazilian state communication model.

KEYWORDS: PUBLIC COMMUNICATION - GOVERNMENTAL COMMUNICATION - STATE COMMUNICATION

\section{Resumen}

El artículo enfoca la comunicación gubernamental en una coyuntura de profunda crisis de legitimidad institucional. En ese escenario, y considerando la historia de la formación del Estado brasileño como un factor a dificultar los cambios necesarios, presenta las propuestas de algunos autores italianos, también desarrolladas al interior de las crisis de aquel país y que pueden contribuir con la elaboración de un modelo brasileño de comunicación estatal.

PALABRAS CLAVES: COMUNICACIÓN PÚBLICA - COMUNICACIÓN GUBERNAMENTAL • COMUNICACIÓN ESTATAL 
inclusão da idéia de globalização na pauta das preocupações empresariais pa-
rece ter sido decisiva para o ingresso da comunicação em posições estratégi-
cas nas organizações de maior porte. Embora jovens, as instituições do terceiro setor também têm se mostrado sensíveis à comunicação estratégica, estabelecendo políticas próprias de planejamento e ação mais baseadas no empirismo cotidiano do que nos estudos sobre o assunto, ainda raros, mas consistentes, no País.

No entanto, quando se observa o Estado, a maior e a mais antiga das organizações nacionais, verifica-se o quanto é atrasado o tratamento dispensado à comunicação, quer no âmbito federal, quer nos âmbitos estaduais e municipais, especialmente se abordados como emissores de informações de interesse público. A demanda existe: no ambiente externo, parte substancial do conteúdo informativo dos meios de comunicação de massa é ocupada com assuntos que envolvem os órgãos públicos estatais. Política, economia, transportes, educação, segurança pública, entre outros, vêm sendo temas prediletos da mídia, variando sua ênfase conforme o perfil de cada audiência. No ambiente interno, as informações se perdem nos meandros da burocracia, não circulam entre funcionários que, nos balcões e nos terminais telefônicos, não sabem o que dizer aos cidadãos. Embora haja exceções como a Companhia do Metropolitano de São Paulo (Metrô-SP) e o programa Poupatempo, ambos ligados ao governo do Estado de São Paulo, elas ainda são raras, dispersas e sem vínculo com diretrizes estabelecidas em políticas de comunicação.

Falar de comunicação pública estatal no Brasil de hoje quer dizer enfrentar a dinâmica de um processo social amplo, que envolve diversos atores e contextos, se a abordagem for a da relação entre o Estado e os cidadãos, relação que se apresenta como confronto, na perspectiva de reconstruir, seja o sentido do Estado, seja o de cidadania. E esta é uma perspectiva difícil de se conseguir nesse cenário dominado por uma profunda crise de legitimidade das instituições, agora mais marcada pelo vendaval de denúncias que parece não acabar nunca.

No entanto, é justamente esta crise de legitimidade um dos fatores capazes de impulsionar mudanças: o Estado deve enfrentar um processo de reconstrução da sua identidade, de modo a parecer confiável e crível; os cidadãos têm a oportunidade de protagonizar um processo de mudança social que tenha no centro a renovação institucional.

Tal processo implica a reconstrução dos mecanismos sobre os quais se sustenta a confiança no Estado como expressão e tutela do interesse da coletividade. Transparência, 
COMUNICAÇÃO GOVERNAMENTAL: EM BUSCA DE UM ALICERCE TEÓRICO

PARA A REALIDADE BRASILEIRA • MARIÂNGELA FURLAN HASWAN

participação, eficiência e eficácia tornam-se, portanto, as palavras de ordem para redesenhar a imagem e o governo das instituições e suas modalidades de relacionamento com os cidadãos. A ação dos poderes públicos vem, deste modo, redefinida em torno do conceito de serviço público e de bem público.

Nessa conjuntura, falar da relação entre as instituições e os cidadãos significa considerar um cenário complexo que mostra uma pluralidade de sujeitos em ação. As administrações públicas são hoje uma realidade em movimento, heterogêneas no seu interior. Não se pode falar de um sujeito institucional, mas dos processos em ação no interior de um contexto articulado e mutante, processos que se diversificam nos âmbitos territoriais e institucionais diversos e que clamam por competência, profissionalismo e capacidades aprimoradas. De outro lado, falar dos cidadãos significa igualmente referir-se a uma realidade complexa e heterogênea. De fato, hoje, eles são melhor representados nas estruturas associativas organizadas da sociedade civil, que têm sido mais competentes que o Estado na defesa dos direitos sociais.

Em seu Tratado de comunicação organizacional e política, Gaudêncio Torquato diz que

"[...] na administração pública, a mentalidade é muito arcaica. Parcela significativa dos funcionários públicos do Brasil pensa de maneira ortodoxa, considera suas repartições um baú velho, e seu trabalho, uma obrigação. Estão ali, mas adormecem mental e psicologicamente no serviço, como se fossem extensões das máquinas. Não se entusiasmam e não usam a criatividade. A comunicação, portanto, padece dessa mazela, a doença da acomodação, a paralisação da malha pública. As instituições públicas são máquinas burocráticas, freqüentemente inertes, paquidérmicas, sofrendo a comunicação com os efeitos das estruturas obsoletas. O desafio da comunicação na instituição pública é aproximar seus serviços da sociedade. Ocorre que a comunicação sozinha não faz milagres. Se o serviço público é ruim, a comunicação não vai consertar a imagem da administração". (2002, p. 83)

Essa, também, parece que tem sido a percepção dos dirigentes das organizações públicas e reformas importantes (da Previdência, do Judiciário, da Política etc.) já vêm sendo discutidas e, algumas vezes, implementadas. Tudo indica, porém, que as transformações no bojo do Estado brasileiro não serão possíveis sem o concurso da comu-

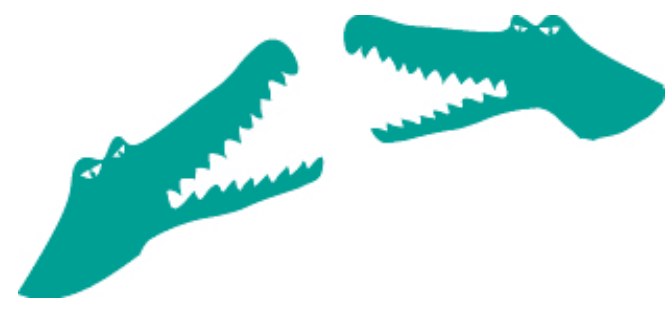


nicação como ferramenta estratégica a oxigenar o organismo estatal em suas relações com a sociedade. Essa constatação flagra o potencial para a Comunicação de modo geral, mas de maneira mais imediata para as Relações Públicas, com o planejamento estratégico e o gerenciamento de crises.

Por todas essas razões, esse artigo lança alguns pontos para a necessária e urgente reflexão teórica sobre a comunicação pública estatal brasileira.

\section{0 público e o privado}

A palavra público faz parte do nosso cotidiano e assume diferentes valores e papéis, dependendo do campo de conhecimento em que sejam analisadas.

No dicionário Houaiss (2000, p. 2330), público aparece significando "1. relativo ou pertencente a um povo, a uma coletividade 2 . relativo ou pertencente ao governo de um país, estado, cidade, etc. 3. o que pertence a todos, comum (por oposição a privado) [...]”, com o primeiro registro escrito do vocábulo datando de 1285 .

Na maioria dos casos, é justamente a reflexão sobre o binômio público/privado que introduz as discussões sobre o conceito de público, do Direito à Administração, da Ciência Política à Psicologia Social.

Para Sandra Jovchelovitch (2000, p. 44), “[...] a noção de esfera pública só pode ser entendida em relação ao seu contrário, isto é, à esfera privada. É, portanto, dentro dessa relação que algo como um espaço público toma corpo”.

Habermas, em Mudança estrutural na esfera pública (1984, p. 16) aponta a cidade-Estado grega e a Europa entre os séculos XVII e XIX como marcos histórico-conceituais da noção de esfera pública. Na pólis, a esfera privada era a domiciliar; ali as pessoas viviam juntas para atender às necessidades vitais, dos ciclos do nascimento à morte, visando tudo o que dissesse respeito às necessidades biológicas da vida. Jovchelovitch explicita com grande clareza esse mesmo conceito ao afirmar que "a vida pública existe precisamente para enfrentar questões de interesse coletivo que não podem ser resolvidas através de caminhos que contêm apenas verdades singulares, radicadas em interesses privados" (JOVCHELOVITCH, 2000, p. 49).

Ao definir o termo público, Hanna Arendt diz que,

"[...] em primeiro lugar, ele quer dizer que o que é público pode ser visto e escutado por todos e possui a maior publicidade possivel; segundo, o termo se refere ao próprio mundo enquanto [sic] algo que é comum a todos os seres humanos e se diferencia do lugar privado que cada pessoa ocupa nele. O mundo, entretanto, não deve ser enten- 
COMUNICAÇÃO GOVERNAMENTAL: EM BUSCA DE UM ALICERCE TEÓRICO

PARA A REALIDADE BRASILEIRA • MARIÂNGELA FURLAN HASWANI

dido como a terra ou como a natureza em estado puro; ao contrário, o mundo é resultado da fabricação de mãos humanas - ou seja, ele se relaciona com o artefato humano e com as questões que se põem para aqueles que vivem neste espaço. O que caracteriza essencialmente o viver partilhado dos seres humanos no mundo é que existe um mundo de objetos entre aqueles que coletivamente o dividem". (apud JOVCHELOVITCH, 2000, p. 50)

Os conceitos distintos de publicus e privatus, herdados dos gregos pelos romanos, não encontraram espaço na Europa medieval, tomada pelas relações de dominação centradas na casa do senhor, capazes de abranger tudo o que existia, inclusive a organização do trabalho social. Para Habermas (1984, p. 17), a representação pública medieval estava imediatamente vinculada à existência do senhor. Não havia uma noção do poder público. A legitimidade do governo era dada pelos atributos pessoais derivados da propriedade da terra ou da linhagem aristocrática. Quando tem início a polarização que antecede a luta da burguesia para firmar-se como alternativa à ordem feudal, lentamente essa visão de público esmaece, dando lugar, no final do século XVIII, à divisão em elementos públicos e privados por parte das autoridades feudais - a Igreja, os príncipes e a nobreza.

É a partir dessa lenta ruptura que se firmam alguns dos conceitos aqui adotados. O primeiro deles é o de que público passa a ser o Estado, revestido de uma existência objetiva em relação à pessoa que o governa. O segundo refere-se à distinção entre público e privado que aparece na Europa, definindo privat (alemão), private (inglês) e privé (francês) como "sem função pública ou oficial", do qual se desenvolve o conceito de "sociedade civil". O terceiro é o de esfera pública, em que indivíduos privados se reúnem para discutir questões de interesse público e são capazes de construir e sustentar uma discussão política de caráter crítico (HABERMAS, 1984, 1989).

A esfera pública introduzida pela revolução burguesa traz consigo a concepção da participação política e da relação entre Estado e sociedade. Ela indica a existência de um espaço em que os cidadãos buscam participação política por meio do diálogo racional sobre as questões de seu interesse. A partir da vitória da burguesia sobre os Estados absolutistas, firmaram-se os objetivos deste novo público de mediar a relação entre Estado e sociedade, fazendo com que o Estado, por meio da publicidade disponível, prestasse à sociedade contas do que fazia. Para Jovchelovitch,

"a prestação de contas [... indicava, no início, o requerimento de que a informação relativa à ação do Estado deveria ser sujeita ao escrutinio da opinião pública. Além disso, ela também indicava que os interesses gerais da sociedade deveriam ser transmitidos a agentes do Estado através de canais legalmente institucionalizados, como a liberdade de imprensa, de palavra e de direito à reunião". (2000, p. 56)

A partir da revolução liberal, a idéia de público torna-se intimamente ligada à concepção de Estado e do exercício de sua autoridade. 
COMUNICAÇÃO GOVERNAMENTAL: EM BUSCA DE UM ALICERCE TEÓRICO PARA A REALIDADE BRASILEIRA • MARIÂNGELA FURLAN HASWANI

\section{O público "privatizado": herança histórica no Brasil}

As considerações sobre uma crise de credibilidade nas instituições estatais no Brasil, mencionadas na abertura desse artigo, ganham novos contornos e maior profundidade à luz da obra de Raymundo Faoro (1998). Ao relatar a história das oligarquias brasileiras e as primeiras manifestações da comunicação do poder público no Brasil, expõe também as origens, na formação do Estado português, da nebulosa fronteira ainda hoje existente entre o que é público e o que é privado:

"A coroa conseguiu formar [...] imenso patrimônio rural [...] cuja propriedade se confundia com o dominio da casa real, aplicando o produto nas necessidades coletivas ou pessoais, sob as circunstâncias que distinguiam mal o bem público do bem particular, privativo do príncipe" (FAORO, 1998, p. 4).

As circunstâncias descritas por Faoro transformaram seu modo de expressão ao longo dos séculos, mas o público e o privado mantiveram, na essência, uma relação promíscua, em que o Estado - representado, após a chegada de Cabral, pela Coroa - lançava mão de toda sorte de benesses públicas capazes de cooptar a minoria representada pela nobreza, pelo clero e pela aristocracia econômica, para o apoio político à Metrópole. No Brasil Colônia, "o alheamento do comando ao povo comandado - alheamento político e cultural - será definitivo, irrevogável, permanente” (FAORO, 1998, p. 202).

Ao chegar ao Rio de Janeiro, D. João VI inaugurou a fase do Império e organizou seu ministério, reproduzindo a estrutura administrativa consolidada em Portugal.

"Tudo se concentrou [...] em situar no mundo político e administrativo os fugitivos desempregados, colocando-lhes na boca uma teta do Tesouro. [...] O eixo da política era $o$ mesmo, secularmente fundido: o reino deveria servir à camada dominante, ao seu desfrute e gozo. Os fidalgos ganharam pensões, acesso aos postos superiores os oficiais da Armada e do Exército, empregos e beneficios os civis e eclesiásticos". (FAORO, 1998, p. 250-251)

Desse modo, o novo governo herdou de Portugal, entre outros vícios, a utilização dos recursos públicos para as necessidades privadas do rei, da elite burocrática do Estado, da nobreza e do clero.

Esta mentalidade atravessou, incólume, as crises políticas geradas pela instabilidade dos primórdios da Independência. "Surge uma ordem metropolitana, reorganizada no estamento de aristocratas improvisados, servidores nomeados e conselheiros escolhidos, que se superporia a um mundo desconhecido, calado, distante" (FAORO, 1998, p. 289).

A Constituição de 1824 traz no seu sistema órgãos de controle criados à imagem e semelhança da configuração monárquica. Dos embates políticos do período resultou um 
parlamentarismo de aparência - inspirado pelo dogma europeu da soberania popular - porque a Coroa mantinha os comandos político e administrativo por meio do poder moderador.

O século entre o primeiro e o segundo reinado trouxe ajustes apenas superficiais ao enraizado sistema político brasileiro. A camada dirigente permaneceu aristocrática na sua função e fechada na perpetuidade hereditária que as leis garantiam.

O que Faoro chama patronato não é, de fato, a aristocracia, mas o aparelhamento, o instrumento em que aquela se expande e se sustenta, em grande parte graças à inércia dos excluídos da burocracia: "sua permanência não convence as inteligências, mas domestica as vontades” (FAORO, 1998, p. 290).

No raiar da Velha República, a instauração do voto direto desloca o eixo do poder para os Estados. Surge e se afirma o coronelismo, com forte vínculo junto às oligarquias estaduais. O coronel era um homem rico, ostentava os bens e exercia o poder político. Mas seu poder não vinha da fortuna, mas do fato de ser um aliciador eleitoral, função acentuada com a passagem do regime imperial para o republicano. Sua tarefa, naquele momento, era converter a opinião republicana, minoritária, em opinião dominante, substituindo a farsa eleitoral monárquica pela farsa eleitoral republicana.

Getúlio Vargas inaugura a Nova República. É o presidente que, para manter o poder, reformula o poder. A insistente segregação imposta ao povo pelas elites fortaleceu os movimentos, estimulados pelo anarquismo e pelo comunismo. O eixo econômico deslocava-se, gradualmente, do setor agrícola para o industrial. Nesse contexto e com a estatização de setores considerados estratégicos, o poder estatal sentia-se em condições de comandar a economia, ainda baseada na formação de uma comunidade burocrática, "agora mais marcadamente burocrática que aristocrática", mas ainda de caráter estamental, superior e capaz de arbitrar as classes. A primeira tentativa é de, sob tutela governamental, disciplinar, jurídica e socialmente, os movimentos operários, uma vez que os grupos dominantes viam-nos como ameaças à ordem pública. Anos mais tarde, a Constituição de 1937 admite que

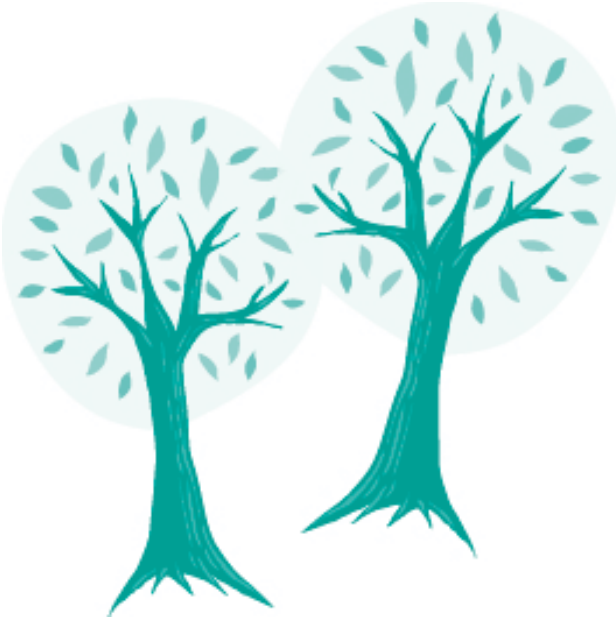


"a intervenção no domínio econômico só se legitima para suprir as deficiências da iniciativa individual e coordenar os fatores da produção, de maneira a evitar ou resolver os seus conflitos e introduzir no jogo das competições individuais o pensamento dos interesses da Nação, representados pelo Estado"(art. 135).

Nesta equação, de movimentos operários sob controle estatal e a Carta Magna permitindo a intervenção estatal na economia, o governo assumiu o papel de "padrinho" dos grandes produtores. Quando as crises econômicas ameaçavam a elite econômica, o governo corria em seu socorro por meio dos bancos oficiais (Banco do Brasil, Caixas Econômicas e instituições de Previdência Social); concediam créditos que, no período inflacionário, tornaram-se verdadeiros subsídios, pois não tinham correção monetária.

Essa diretriz atravessou todo o século XX. A roupagem evoluiu, sem dúvida alguma. As vagas públicas destinadas aos filhos da corte e da aristocracia imperiais tornaramse "cargos em comissão", popularmente chamados de "cargos de confiança". Essas vagas são sempre de comando, dispensam a participação dos candidatos em concursos públicos e são ocupadas por indicados pelos mandatários eleitos. No governo federal, somam mais de 20 mil e na capital paulista, só na administração direta, 10.192 cargos em comissão. ${ }^{1}$

Com base nessa história em que o Estado usa benesses públicas como armas de sedução e/ ou de cooptação de lideranças ignorando a evolução paralela dos meios de comunicação para seu relacionamento com a sociedade e para com os cidadãos, parece natural que a comunicação estatal seja incipiente, ineficiente e, não raro, inadequada, refletindo-se, inclusive, no meio acadêmico brasileiro, em que não encontramos linhas de pesquisa específicas sobre o tema.

Hoje, porém, as instituições estatais, acuadas por uma opinião pública cada vez mais madura, mostram disposição para implementar reformas capazes de refletir por toda a sua estrutura. Neste contexto, parece oportuno lançar algumas bases para reflexões sobre sua comunicação. E, quem sabe, resgatar o tempo perdido.

\section{A comunicação pública}

As obras editadas em língua portuguesa sobre o assunto, no Brasil, embora constituam uma contribuição respeitável para a compreensão de aspectos da comunicação pública, não interagem entre si; começam e terminam nos domínios de suas próprias re-

1 Os dados federais foram obtidos no Boletim Estatístico do Ministério do Planejamento, no 87, jul. 2003. Os dados municipais, armazenados no Sistema Informatizado de Recursos Humanos (SIRH), foram fornecidos pela diretoria da Divisão de Ingresso e Controle de Quadros, do Departamento de Recursos Humanos da Secretaria Municipal de Gestão Pública. 
COMUNICAÇÃO GOVERNAMENTAL: EM BUSCA DE UM ALICERCE TEÓRICO

PARA A REALIDADE BRASILEIRA • MARIÂNGELA FURLAN HASWANI

flexões, dificultando a construção de pressupostos teóricos capazes de fundamentar satisfatoriamente esse trabalho. ${ }^{2}$

Já entre os pesquisadores italianos ${ }^{3}$, as reflexões sobre a comunicação pública firmamse nos limites do Estado, quer como ente político, quer como instância administrativa. O destinatário algumas vezes é considerado cidadão, outras vezes usuário dos serviços públicos ou simplesmente alvo da programação realizada para formar e consolidar a imagem da instituição pública emissora das informações.

A definição de Roberto Grandi (2002) articula-se sobre a delimitação do campo da comunicação de massas proposta por Harold Lasswell (1948), por meio de uma pergunta conhecida como o postulado de Lasswell: "Who says what in what channel to whom with what effect?" - quem diz o quê, em que canal, a quem e com que efeito?

- Quem - a comunicação da instituição pública é aquela realizada pela administração pública (ou ente público ou serviço público); esta atribuição deve poder ser operada por qualquer um, mediante a presença, explícita e clara, da assinatura da fonte;

- Diz o quê-divulga a produção normativa, as atividades, a identidade e o ponto de vista da administração;

- Por meio de que canais-utiliza, possivelmente de maneira integrada, todas as midias disponiveis $[\ldots]$;

- A quem - aos cidadãos ou às organizações, quando se apresenta como comunicação externa direta; aos meios de comunicação de massa, quando quer atingir os cidadãos e as organizações que constituem a audiência destes meios; a quem atua, como público interno, nas instituições públicas, quando se apresenta como comunicação interna;

- Com que efeitos - garantir aos cidadãos o direito de informação (principalmente aquele direito de se informarem e de serem informados); construir e promover a identidade do ente público para reforçar as relações entre os subordinados e a administração, de um lado, e entre os cidadãos e seus semelhantes, de outro; oferecer aos cidadãos a possibilidade de exprimir de maneira ativa e substancial os direitos de cidadania, a fim de se tor-

2 Entre as dezenas de estudiosos que publicaram no Brasil e em língua portuguesa obras que tratam direta ou indiretamente da Comunicação Pública, estão Ignácio Ramonet, com Tirania da comunicação; Maria Helena Capelato, com Multidões em cena; Cremilda Medina, como organizadora de A comunicação na Nova República; Perseu Abramo, com Padrões de manipulação na grande imprensa; Margarida Kunsch, com Planejamento de Relações Públicas na Comunicação Integrada; Gaudêncio Torquato, com diversas obras, entre as quais Comunicação Empresarial/Comunicação Institucional, Jornalismo Empresarial e Tratado de Comunicação Organizacional e Política.

3 Praticamente em todas as universidades italianas existe alguma linha de pesquisa em Comunicação Pública, inclusive no concernente ao público não estatal. Entre os autores aqui citados, pode-se ter uma amostra: Roberto Grandi é da Universidade de Bologna; Franca Faccioli, da Universidade de Roma "La Sapienza"; Stefano Rolando, da Universidade Iulm de Milão, onde leciona Teoria e Técnica da Comunicação Pública e Comunicação de Utilidade Pública. 
narem co-responsáveis pela solução dos problemas de interesse geral; produzir uma mudança radical de mentalidade interna da administração pública, que deverá ter a comunicação como recurso estratégico para a definição das relações com os cidadãos. (GRANDI, 2002, p. 55)

Nessa análise, além de descrever o amplo espectro de cobertura da comunicação pública, Grandi aponta aspectos particularmente relevantes: ao definir o setor público como emissor, fortalece a natureza institucional da comunicação quando afirma que qualquer pessoa ou órgão pode ser operador da emissão, desde que a assinatura (institucional) esteja presente: cidadãos e organizações como destinatários das mensagens do setor público; também, a dupla natureza da informação emitida pelo setor público - informação e formação (de opiniões, atitudes, comportamentos).

Stefano Rolando, partindo de sua experiência como diretor geral na presidência do Conselho dos Ministros, na Itália, amplia a abordagem de Grandi, em função dos segmentos dos destinatários, dos conteúdos, dos meios utilizados, das dimensões econômicas, do tempo de duração e da extensão espacial, apontando dezoito tipos de comunicação institucional para a área pública, depois sucessivamente reagrupados por ele até se resumirem em cinco frentes de atuação:

- a publicidade institucional (aquela obrigatória, dever do Estado);

- a publicidade de normas e leis;

- a publicidade dos serviços públicos novos ou específicos;

- a publicidade das atividades ou do funcionamento da estrutura [...];

- a publicidade ${ }^{4}$ de imagem e de promoção (ligada a turismo, cultura e identidade corporativa). (ROLANDO, 1990, p. 102-3)

Para Franca Faccioli (2000, p. 44), a comunicação feita pelas instituições públicas atende a duas exigências: informar os cidadãos sobre seus direitos e responder à demanda de transparência, de um lado, e promover os processos de inovação institucional, de outro. Para alcançar esses objetivos, a comunicação da instituição pública limitase a funções precisas:

"informar seus próprios funcionários, escutar as exigências dos cidadãos, contribuir para reforçar a relação social, valorizar o cidadão como ator dos processos de mudança e acompanhar a mudança, tanto dos comportamentos quanto da organização social". (FACCIOLI, 2000, p. 58)

Ela também propõe uma classificação da comunicação pública estatal, caracterizada em cinco dimensões, parcialmente sobrepostas:

4 Publicidade, aqui, é usada no sentido de tornar público, dar o conhecimento a. 
- A comunicação normativa - apresentada como base da comunicação pública, considerando que o conhecimento e a compreensão das leis são a pré-condição para uma relação consciente entre os órgãos públicos e os cidadãos. A natureza da comunicação normativa, porém, apresenta dois obstáculos: um, de caráter puramente semântico, aponta a obscuridade da linguagem administrativa; outro, referente ao processo de publicação, trata dos instrumentos utilizados para divulgar esses textos para os cidadãos.

- A comunicação da atividade institucional "faz referência à ilustração da atividade das instituições do Estado e em particular da administração [...] com um cargo específico ocupando-se da comunicação do governo" (2000, p. 48). Faccioli constata, também, que a comunicação sobre a política e sobre a atividade do governo é aquela que apresenta maiores obstáculos e limites de continuidade, talvez induzidos pelo "temor de cair nos procedimentos de propaganda".

- A comunicação de utilidade pública, ao contrário, caracteriza-se pela dimensão específica do serviço e se destina "em primeira instância a facilitar aos cidadãos o contato com a administração pública e a utilização dos serviços públicos”.

- A comunicação para a promoção da imagem é aquela que lembra as políticas de construção da imagem empresarial adotadas no mercado privado; nesse campo, a autora critica o fato de não existir sempre este espaço da "estreita relação" que, em se tratando de setor público, não deve ser "só uma campanha de promoção de imagem de um ente que diz (coisas), mas sim que o que o mesmo ente faz" (2000, p. 54).

- A comunicação social se inclui entre as dimensões da comunicação pública porque supõe que, por se tratar do mesmo âmbito da "comunicação de solidariedade social realizada na área sem fins lucrativos", ou seja, "os grandes temas sociais sobre cuja intersecção é necessário sensibilizar a opinião pública” a respeito "do papel dos atores e dos objetivos que se queira alcançar”. Tais temas são promovidos pelas instituições do Estado "que se propõem a dar elementos de conhecimento e conscientização aos cidadãos em relação a problemas de interesse coletivo, também na perspectiva de convencê-los a modificar seus comportamentos" (2000, p. 54).

O pensamento desses autores aparece, de certo modo, sintetizado na proposta de Gregório Arena (1999), que apresenta todo o campo da comunicação das instituições públicas em três divisões:

- A comunicação jurídica-formal que, tendo como objeto a regulamentação jurídica das relações entre os membros do comando, serve para "aplicar normas, dar segurança, obter conhecimento de um ato jurídico e outras atividades similares” (p. 19).

- A comunicação de serviço destina-se, principalmente, "a informar os usuários sobre as modalidades de funcionamento dos setores, sobre o regulamento aplicado a cada um deles e o serviço oferecido". O caráter de serviço dessa informação apresenta-se sob dois pontos de vista: são informações que, por si só, já constituem um 


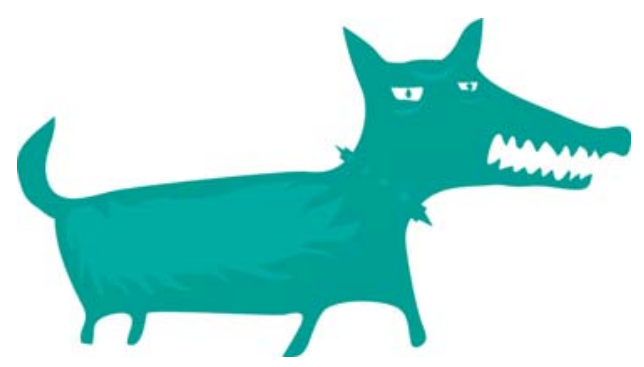

serviço aos usuários e são, ao mesmo tempo, parte do serviço oferecido pela administração. No primeiro caso, Arena lembra que, nos dias de hoje, é dever de uma administração fornecer informações aos usuários, o mais claramente possível, a respeito das regras e da própria atividade: "É responsabilidade da administração não somente fornecer o serviço, mas também oferecer as instruções para o uso do mesmo serviço, sem deduzir, como acontece freqüentemente, que o usuário já tenha conhecimento das regras" (p. 20). No segundo caso - das comunicações como parte integrante do serviço oferecido pela administração - deve-se salientar que se trata das comunicações que incidem sobre a qualidade do serviço, condicionando-lhe a modalidade de utilização e o usufruto do serviço obtido por parte dos interessados.

- A comunicação administrativa ou comunicação de cidadania é considerada por Arena "a mais significativa para a realização do modelo de administração partilhada". Essa comunicação se diferencia da anterior pelo seu próprio objetivo: "não serve [...] para regular relações jurídicas ou para informar sobre um fato da vida cotidiana, mas para resolver um problema de interesse geral". Sempre, conforme Arena, a definição de comunicação administrativa se apresenta como um instrumento graças ao qual a administração pode atuar convencendo, enquanto a definição de comunicação de cidadania enfatiza mais o fato de que, por meio desse tipo de comunicação, "a administração vai para, não os usuários nem os clientes, mas para os cidadãos, os sujeitos que, como membros de uma comunidade, são também titulares dos direitos e dos deveres, entre os quais aquele de contribuir, nos limites de suas possibilidades, para a solução dos problemas de interesse geral” (1999, p. 21). Exemplos de problemas de interesse geral que Arena caracteriza como solucionáveis são aqueles que cuidam da tutela ambiental, da saúde, da previdência, da educação, do emprego, da segurança viária, da ordem pública, da eliminação do lixo, da circulação das pessoas e dos produtos.

\section{Conclusão}

Seria pretensão tirar conclusões a partir das tão breves considerações apontadas nesse estudo. Mas elas nos remetem a, pelo menos, duas reflexões. 
COMUNICAÇÃO GOVERNAMENTAL: EM BUSCA DE UM ALICERCE TEÓRICO

PARA A REALIDADE BRASILEIRA • MARIÂNGELA FURLAN HASWANI

A primeira, de que o atraso verificado na comunicação pública estatal brasileira tem suas raízes fincadas numa história em que as autoridades constituídas praticamente ignoravam a existência da sociedade situada fora das suas hostes apadrinhadas e, portanto, não desejavam nem necessitavam ser emissoras de mensagens para seu ambiente externo. Do outro lado, segregada dos centros do poder estatal e das informações sobre decisões políticas ou sobre serviços públicos até quase meados do século passado, a própria sociedade parece ter permanecido acomodada, sem ter ou sem manifestar sua força como opinião pública.

A segunda considera justamente a consciência cidadã que a sociedade vem adquirindo em relação ao Estado, seu papel e suas obrigações. Passa, então, a ser agente transformador porque é capaz de cobrar, de denunciar ou, simplesmente, solicitar aos órgãos estatais informações precisas sobre assuntos de seu interesse. E no momento em que ela tem o poder do voto, as forças políticas do Estado passam a necessitar e a desejar o papel de emissoras de mensagens, especialmente quando os movimentos da sociedade civil passam a se constituir em forte base social organizada, crítica e formadora da opinião pública.

Considerados à luz das propostas de Faccioli, Grandi e Rolando, tais aspectos sugerem a necessidade de revisão, pelo Estado brasileiro e pelos pesquisadores do assunto, do papel que a comunicação desempenha junto à sociedade e, também, repensála como recurso estratégico capaz de produzir a mudança radical de mentalidade interna da administração pública, para a definição das relações com os cidadãos - numa síntese do pensamento dos três autores.

A legitimidade e a credibilidade estatais colocadas em xeque-mate pelas informações sobre corrupção, má administração de recursos públicos, exercício de "compadrismo", entre outras, parecem constituir um cenário oportuno para consolidação das experiências de comunicação estatal já implantadas com sucesso e para a gestação de novos rumos e políticas para essa área tão fundamental e tão mal cuidada nas organizações estatais e tão pouco estudada no meio acadêmico.

\section{Bibliografia}

ARENA, G. // nuovi diritti all'informazione. 2.ed. Milão: Twin Book, 2003.

ARISTÓTELES. A política. Rio de Janeiro: Ed. de Ouro, 1965.

AZAMBUJA, D. Teoria geral do Estado. 43. ed. São Paulo: Globo, 2001.

DALLARI, D. A. Elementos de teoria geral do Estado. 24. ed. São Paulo: Saraiva, 2003.

FACCIOLI, F. Communicazione pubblica e cultura del servizio. Roma: Carocci, 2000. 
COMUNICAÇÃO GOVERNAMENTAL: EM BUSCA DE UM ALICERCE TEÓRICO

PARA A REALIDADE BRASILEIRA • MARIÂNGELA FURLAN HASWANI

FAORO, R. Os donos do poder: formação do patronato político brasileiro. 13. ed. São Paulo: Globo, 1998. 2 v.

FREYRE, G. Sobrados e mucambos: decadência do patriarcado rural e desenvolvimento do urbano. 2. ed. Rio de Janeiro: José Olympio, 1951.

GRANDI, R.. La comunicazione pubblica. 2. ed. Roma: Carocci, 2002.

HABERMAS, J. Mudança estrutural da esfera pública: investigações quanto a uma categoria da sociedade burguesa. Rio de Janeiro: Tempo Brasileiro, 1984.

JOVCHELOVITCH, S. Representações sociais e esfera pública: a construção simbólica dos espaços públicos no Brasil. Petrópolis: Vozes, 2000.

LUDUVIG, M. M. As transformações do jornalismo empresarial na década de 80 aos dias atuais. 1994. Dissertação (Mestrado em Jornalismo e Editoração) - Escola de Comunicações e Artes. São Paulo: Universidade de São Paulo, 1994.

MIGUEL JORGE. Comunicação: a favor da reserva de competência. Gazeta Mercantil, São Paulo, 1990.

PERFIL revisto e ampliado. Revista Brasileira de Comunicação Empresarial. São Paulo: Aberje, n.13, p 4-7, 1994.

PINHO, Ruy Rebello. Instituições de direito público e privado. 18. ed. São Paulo: Atlas, 1992.

REALE, Miguel. Teoria do direito e do Estado. 2. ed. São Paulo: Martins, 1960.

REGo, F. G. Torquato do. Tratado de comunicação organizacional e política. São Paulo: Pioneira Thomson Learning, 2002.

ROLANDO, S. Teoria e tecniche della comunicazione pubblica. 2. ed. Milão: ETAS, 2003.

SÃO PAULO (cidade) Secretaria Municipal do Planejamento. Guia de serviços públicos da cidade de São Paulo 2002. São Paulo, 2000. 404 p., il. Inclui mapas.

\section{$\mathrm{Na}$ Internet}

<http://www.brasil.gov.br>. Acessos em 17 jan. 2006 e 3 fev. 2006.

<http://www.senado.gov.br>. Acesso em 15 mai. 2005.

<http://www.saopaulo.sp.gov.br>. Acessos em 20 jul. 2004 e 10 jan. 2005.

<http://www.portal.prodam.sp.gov.br>. Acessos em 05 ago. 2005 e 10 jan. 2006.

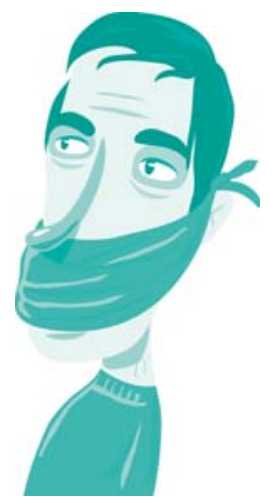

